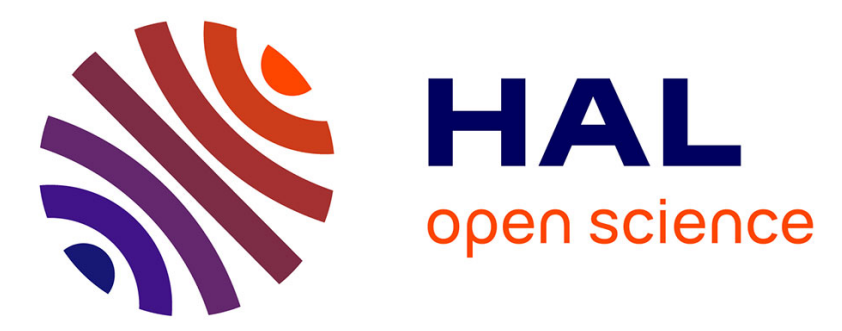

\title{
Oceanic primary production .1. Adaptation of a spectral light-photosynthesis model in view of application to satellite chlorophyll observations
}

\author{
D Antoine, A Morel
}

\section{- To cite this version:}

D Antoine, A Morel. Oceanic primary production .1. Adaptation of a spectral light-photosynthesis model in view of application to satellite chlorophyll observations. Global Biogeochemical Cycles, 1996, 10 (1), pp.43-55. 10.1029/95GB02831 . hal-03284962

\section{HAL Id: hal-03284962 \\ https://hal.science/hal-03284962}

Submitted on 28 Dec 2021

HAL is a multi-disciplinary open access archive for the deposit and dissemination of scientific research documents, whether they are published or not. The documents may come from teaching and research institutions in France or abroad, or from public or private research centers.
L'archive ouverte pluridisciplinaire HAL, est destinée au dépôt et à la diffusion de documents scientifiques de niveau recherche, publiés ou non, émanant des établissements d'enseignement et de recherche français ou étrangers, des laboratoires publics ou privés.

$$
\text { Copyright }
$$




\title{
Oceanic primary production
}

\section{Adaptation of a spectral light-photosynthesis model in view of application to satellite chlorophyll observations}

\author{
David Antoine and André Morel \\ Laboratoire de Physique et Chimie Marines, Université Pierre et Marie Curie et CNRS, Villefranche sur Mer, France
}

\begin{abstract}
A global equation, designed to estimate the column-integrated oceanic primary production realized by a given phytoplankton biomass under various environmental conditions, is used to develop a practical method to assess the primary production $(\mathrm{P})$ from the chlorophyll concentration as provided by satellite imagery. This basic equation combines three terms, namely the photosynthetically available radiation impinging at the sea surface, PAR $\left(0^{+}\right)$, the column-integrated chlorophyll content, $\langle\mathrm{Chl}\rangle_{\text {tot }}$, and the cross section for photosynthesis per unit of chlorophyll, $\Psi^{*}$. Global monitoring of incident irradiance and near-surface algal biomass is now achievable from space, and thus the next step toward a monitoring of oceanic primary production would be to dispose in parallel of a "climatological field" of the $\Psi^{*}$ quantity. Actually, $\Psi^{*}$ depends on the two other terms of the equation (PAR $\left(0^{+}\right)$and $\langle\mathrm{Chl}\rangle_{\text {tot }}$ ), and, in addition, on temperature (also detectable from satellite). Therefore such a "climatological field" is variable and complex and it can be conveniently replaced by lookup tables allowing easy interpolation. The entries are date, latitude, cloudiness, temperature, and remotely sensed chlorophyll concentration. This upper layer concentration is extended downward owing to previous results of a statistical analysis of the chlorophyll vertical distribution; accordingly, two parallel tables, corresponding to well-mixed or stratified upper layers with uniform or non uniform chlorophyll vertical profiles, respectively, are constructed. These tables are produced by systematically using a previously published spectral light-photosynthesis model. For such extensive computations, the model necessarily relies on, and is operated with, a standard set of ecological and physiological parameters. Therefore sensitivity analyses have been carried out in view of assessing the impact on $\Psi^{*}$, and on the resulting production of deviations in these parameters or parameterizations, vis-a-vis the standard values or formulations which were adopted when building the tables. The effects of the biomass vertical structure, of possible light and temperature adaptation, and of the presence of degraded pigments are among the sensitivity studies which have been performed. The method as proposed can accomodate any improvement and complexity in parameterization to the extent that additional computation time is faced only when generating the lookup tables, not when using them in conjunction with satellite data.
\end{abstract}

\section{Introduction}

The primary production rate of any plant biomass first depends on the size of the biomass itself and on the amount of radiant energy impinging onto this biomass and able to drive the photosynthesis process. In an aquatic environment, the phytoplankton stock actually evolves as a result of the balance between the net photosynthetic carbon fixation and all the processes responsible for its degradation and consumption (decay, sinking, grazing). The present paper deals only with the first process, that is, the increase in the algal carbon pool, whatever its actual fate. At a given moment, the water column primary production can be mechanistically described in a compact and diagnostic form through [Morel, 1978, 1991]

$$
\operatorname{PSR}=<\mathrm{Chl}\rangle_{\text {tot }} \operatorname{PAR} \psi^{*}
$$

Copyright 1996 by the American Geophysical Union.

Paper number 95GB02831.

0886-6236/96/95GB-02831\$10.00 where the algal biomass is quantified as being the column-integrated chlorophyll content, $\langle\mathrm{Chl}\rangle_{\text {tot }}$ in grams of chlorophyll per square meter, where PAR (Joules per square meter) is the photosynthetically available radiant energy (within the spectral range $\lambda$ $=400$ to $700 \mathrm{~nm}$ ) incident at the sea level per unit area and during a given lapse of time (e.g. 1 day), and where PSR (Joules per square meter) is the energy photosynthetically stored (during the same duration) as chemical energy within the plant biomass throughout the water column of unit section. The height of this column corresponds to the productive layer, in which the net photosynthesis is positive for the timescale considered. According to the structure of (1), the factor $\Psi^{*}$ has the dimension of a cross section of algae for photosynthesis and per unit of areal chlorophyll biomass; it is expressed as $\mathrm{m}^{2}(\mathrm{~g} \mathrm{Chl})^{-1}$. The single quantity $\Psi^{*}$ actually merges the two basic processes involved in the photosynthetic carbon fixation, namely the capture of radiant energy and then the transformation of this harvested energy into chemical energy stored in the algal biomass. The carbon fixation, $P$ (expressed as mass of $\mathrm{C}$ fixed per area and time units) and PSR are related through 


$$
\mathrm{P}=\mathrm{PSR} / \mathrm{J}_{\mathrm{C}}
$$

where $J_{C}$ represent the energetic equivalent of photosynthetic assimilate (expressed as $\mathrm{kJ}\left(\mathrm{g} \mathrm{C}^{-1}\right)$. The same quantity relates $\Psi^{*}$ to the "light utilization index", $\Psi$, introduced by Falkowski [1981] according to

$$
\Psi=\Psi^{*} / J_{C}
$$

where $\Psi$ is expressed as $\mathrm{g} \mathrm{C}\left(\mathrm{g} \mathrm{Chl}^{-1}\left(\mathrm{~J} \mathrm{~m}^{-2}\right)^{-1}\right.$.

An important application of the remotely sensed images of ocean color is the estimation of the oceanic primary production based on chlorophyll pigments fields as derivable from such a spectroradiometric technique. The surface solar irradiance and its photosynthetically active portion can be computed under clear sky conditions from astronomical parameters (solar declination, SunEarth distance, geographical latitude) and atmospheric properties [see e.g., Frouin et al., 1989 ; Gregg and Carder, 1990 ; Tanré et $a l ., 1990]$. In the frame of the International Satellite Cloud Climatology Project (ISCCP) [Schiffer and Rossow, 1983, 1985], observations from multiple spaceborne sensors are permanently combined to provide a global monitoring of the occurence of clouds and of their optical properties. The solar irradiance under cloudy skies can also be estimated by using these data. The clear sky and cloudy sky components can then be added to produce total solar irradiance fields over the ocean at the appropriate timescales, from days to months and years [Bishop and Rossow, 1991; Pinker and Laszlo, 1992]. In reference to (1), the next step toward assessing the oceanic primary production, with an efficiency adapted to that offered by the continuous and global views of biomass and irradiances as provided by satellites, would be to dispose in parallel of a global climatological field of the parameter $\Psi^{*}$. This approach was already suggested by Berthon and Morel [1992], and used at mesoscale for a study of the Mediterranean Sea [Morel and André, 1991; Antoine et al., 1995]. The aim of the present work is twofold : (1) to develop a method allowing the production of a $\Psi^{*}$ field, based on a set of standard values given to the physiological parameters controlling the photosynthesis response of algae, (2) to assess, through sensitivity analyses, the impact of deviations in these parameters vis-a-vis their standard values on the resulting $\Psi^{*}$ values and therefore on the production estimates.

In prevision of use in combination with chlorophyll as sensed by satellite, the $\Psi^{*}$ field as well as the resulting production are conveniently made available under the form of tabulated values. In a companion paper this method is applied to the coastal zone color scanner (CZCS) archive; by using the lookup tables in conjunction with the monthly mean global chlorophyll images, the oceanic primary production can be assessed, and its seasonal evolution studied at the scale of the world ocean.

\section{Theoretical and Computational Background}

In counterpart of the formal simplicity of (1), the single $\Psi^{*}$ term conceals all the complexities inherent to the physical and physiological mechanisms involved in the marine carbon fixation process. It primarily includes a representation of the local and instantaneous photosynthetic response of phytoplankton to the light climate, namely to the amount and spectral composition of radiant energy. Then it cumulates these responses of algae, which are living at different depths within the productive layer, and accounts for the varying radiation availability along the light period. Therefore $\Psi^{*}$ is a bulk quantity which describes the global response of a given column-integrated biomass when lighted according to prescribed conditions prevailing above the surface. From the above remarks, it follows that $\Psi^{*}$ is not an independent term, separable from the two others, $\langle\mathrm{Chl}\rangle_{\text {tot }}$ and PAR, appearing in (1), as briefly explaint d below (see details in Appendix A).

At time $t$, and depth $z$, the amount of monochromatic $(\lambda)$ irradiance which drives photosynthesis, denoted $\operatorname{PAR}(\lambda, t, z)$ depends on the corresponding value at the sea surface, $\operatorname{PAR}(\lambda, t, 0)$, and then on attenuation along the path from 0 to $z$. The light attenuation is ruled, at least for oceanic case 1 waters [Morel, 1988], by the pigment vertical profile, $\mathrm{Chl}(z)$. To the extent that

$$
\int_{0}^{\operatorname{L}} \int_{400}^{700} \operatorname{PAR}\left(\lambda, t, 0^{+}\right) \mathrm{d} \lambda \mathrm{d} t=\operatorname{PAR}\left(0^{+}\right)
$$

and $\left.\quad \int_{0}^{\mathrm{D}} \operatorname{Chl}(z) \mathrm{d} z=<\mathrm{Chl}\right\rangle_{\text {tot }}$

$\Psi^{*}$, as depending on the two integrands, is implicitly related to the integrated quantities $\operatorname{PAR}\left(0^{+}\right)$and $\langle\mathrm{Chl}\rangle_{\text {tot }} ; \mathrm{L}$ is the day length; 0 means just above the surface and $D$ is the depth of the productive layer. A lookup table providing climatological $\Psi^{*}$ values must account first for the varying environmental conditions that determine $\operatorname{PAR}(\lambda, t, 0)$, and second for the various ecological or trophic situations described by the chlorophyll profile, $\mathrm{Chl}(z)$. The past history (vertical mixing, light and nutrient availability, grazing pressure) results in a given algal biomass with a given vertical structure. This history does not interfere with the computation presently envisaged which only deals with the potential carbon incorporation by the present biomass. In no way such a computation constitutes a predictive model of algal evolution.

In a first approximation, the day of the year, the latitude and the cloudiness index (three variables) suffice for predicting $\operatorname{PAR}(\lambda, t, 0)$ and the daily integrated amount $\operatorname{PAR}\left(0^{+}\right)$(equation 3 ). The aerosol, ozone and, with a lesser importance for the spectral range involved, the water vapor content could be three additional variables (not considered here). The vertical pigment profile is also needed (4). In the perspective of using remotely sensed data, and because the concentration detectable from space is restricted to the upper layer [Gordon and McCluney, 1975; André, 1992], further assumptions are required. Following a previous approach [Morel and Berthon, 1989], two cases are considered. When the mixed layer is presumed to be thicker than the productive layer, $\mathrm{Chl}(z)$ is supposed to be constant and everywhere equal to the

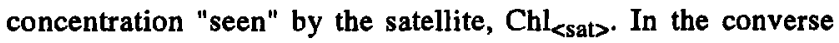
situation, when a stratification occurs inside the productive layer, the vertical profile may, and often does include a deep chlorophyll maximum (DCM). The magnitude and position of this maximum are made variable according to the upper layer value, $\mathrm{Chl}_{\text {<sat }}$ (equation (6) Morel and Berthon [1989]). In both situations, the integration over the productive layer provides $\langle\mathrm{Chl}\rangle_{\text {tot }}$ (see Appendix B). The discrimination between the two cases rests on external information (climatology or sea surface temperature evolution, as remotely sensed).

Temperature is also known to react on the maximal photosynthetic capacity of algae. As the temperature effect is imbedded inside the parameterization of the light response (Appendix A), its influence cannot be separately treated. It is therefore another entry for a lookup table providing $\Psi^{*}$. Selecting the most appropriate value for temperature (either sea surface of mean water column 
temperature, for instance) remains an open question and is incumbent upon each user of the table. However, as $\Psi^{*}$ is computed under the assumption of uniform vertical temperature profiles, entering into the tables with the mean temperature over the euphotic zone appears as a reasonable choice [see Antoine et al., this issue].

Finally, and under the hypothesis of a single (mathematical) representation of the photosynthetic response (Appendix A; equation (A6)), two parallel, five-dimensional tables are necessary to account for the two possible options relative to the pigment profiles. They provide $\Psi^{*}$ and $P$ values as a function of date, latitude, cloudiness, temperature, and $\mathrm{Chl}_{<s a l}$. Computing such tables requires the adoption of a "standard" parameterization of all phases of the photosynthesis process (Appendix D). This parameterization follows an approach previously developed [Morel, 1991]. For the sake of completeness and in support to the sensitivity studies, the basic definitions and equations are recalled in Appendix A. The way of generating the lookup tables is described below, then the effects of changing the parameterization itself or of modifying the numerical values given to the parameters, are examined as sensitivity studies.

At this stage it is worth emphasizing that the model used to obtain the $\Psi^{*}$ values is based on a set of fixed equations and prescribed parameterizations (see Appendices A, B, and D). Once this set is introduced, the model provides, in each particular case, a unique solution for $\Psi^{*}$ and then for $\mathrm{P}$. In this sense, there is no "error bar" on $\Psi^{*}$. Changing one-by-one input parameters, as done in sensitivity tests, allows the variations in $\Psi^{*}$ to be quantified, not in terms of error, but in terms of uncertainty which numerically results from possible deviations between actual and adopted parameters.

\section{Generating the Lookup Tables for $\Psi^{*}$}

The values of the physiological parameters presently adopted (Appendix D) differ from those initially used by Morel [1991], and also from those resulting from a first validation of the model [Berthon and Morel, 1992]. In a recent additional validation test, the outputs of the model, when operated with the previous set of parameters, have been compared to repeated primary production measurements (JGOFS-EUMELI cruises in the tropical North Atlantic). These in situ determinations were made by using clean techniques [Dandonneau and LeBouteiller, 1992] in two (oligotrophic and eutrophic) contrasted regimes. The model data comparison has shown that if the model accounts well for the column-integrated production, it systematically underestimates the actual $C$ fixation within the upper part of the euphotic zone and conversely overestimates it at low irradiance levels. A better reconstrüction of the $\mathrm{C}$ fixation profile can be obtained by slightly modifying the set of physiological parameters (this change does not significantly alter the integrated primary production). Accordingly, this new set has been presently preferred. It also relies on recent findings [Wozniak et al., 1992; Bricaud et al., 1995] about the rather regular and opposite variations of the maximum quantum yield, $\varphi_{\mu, \max }$, and the maximum chlorophyll specific absorption coefficient, $\mathrm{a}^{*}$ max , along with the chlorophyll concentration. From oligotrophic to eutrophic regimes, that is, when the chlorophyll concentration increases, $\varphi_{\mu, \max }$ tends to increase, whereas $\mathrm{a}^{*}{ }_{\max }$ tends to decrease, so that their product remains roughly constant (see Appendix D). It must be emphasized that $P$ is to the first-order and linearly related to the product $\mathrm{a}^{*}$ max $\varphi_{\mu, \text { max }}$, appearing outside of the integral of (A9) (Appendix A), so that there is no need for any "sensitivity" study concerning either each term separately considered or the product of both.

The depth of the productive layer adopted for the computations, D, is that depth where PAR is reduced to $0.1 \%$ of its surface value. $\mathrm{D}$ is computed by using the $\mathrm{Chl}(z)$ profile adopted (uniform or not, Figure 1a), and by propagating the downwelling irradiance throughout the water column according to the scheme proposed by Morel [1988] for case 1 waters. The downwelling irradiance is then transformed into scalar irradiance (via a "geometrical factor", detailed by Morel [1991]) to obtain PAR. The depth $D$ is approximately 1.5 times $Z_{e}$, the commonly defined euphotic depth (the so-called "1 \% light level"). The consideration of deeper levels is necessary because deep chlorophyll maxima often develop at levels close to $Z_{e}$ and persist over long periods in many parts of ocean [Cullen, 1982]. The inclusion of deep layers, from $Z_{e}$ down to $D$, results in increasing the column-integrated biomass, $\langle\mathrm{Ch}\rangle_{\text {tot }}$, and correlatively in lowering the $\Psi^{*}$ values with respect to those which would be predicted for a layer restricted to $Z_{\mathrm{e}}$. Nevertheless, the product $\Psi^{*}$ $\langle\mathrm{Chl}\rangle_{\text {tot }}$ and then the production (equation (1a)) are slightly enhanced in oligotrophic waters exhibiting a strong DCM around or below the $1 \%$ level, whereas they remain practically unchanged for mesotrophic and eutrophic waters.

The $\langle\mathrm{Chl}\rangle_{\text {tot }}$ values are computed (through equation (4)), either by letting $\mathrm{Chl}(z)=\mathrm{Chl}_{<s a t>}$ everywhere from $z=0$ to $z=\mathrm{D}$, or by using non uniform profiles as shown in Figure 1a. These computations can be made once after which two relationships between $\langle\mathrm{Chl}\rangle_{\text {tot }}$ and $\mathrm{Chl}_{<s a b}$ are derived by least square fit to polynomial expressions (given in Appendix B).

The photosynthetically active radiant energy impinging at the ocean surface and under clear skies is estimated by using the " $5 \mathrm{~S}$ model" [Tanré et al., 1979, 1990] together with standard atmospheric conditions (Appendix D). The reduction of the incident PAR radiation due to the presence of clouds is estimated according to the formulation of Reed [1977], when modified to account for the less severe reduction by clouds of the visible radiation; this reduction is assumed to be only $75 \%$ of that affecting the solar near infrared radiation (see Appendix $C$ ). The computation of PAR and subsequent computations have been made for all latitudes between the north pole and $76.25^{\circ}$ south (Table 1) and for the twenty-first day of each month in order to include the two extrema found in both hemispheres at the two solstices. Half a year and only one hemisphere could have been considered. In such a case, however, a correction for the ellipticity of the Earth's orbit should have been necessary as the incident solar flux is varying by $\pm 3.4 \%$ around its mean value according to the date of the year. For convenience, it is better to dispose of a full table with all dates and latitudes.

\section{Results}

\section{General Overview of Table Content}

The lookup tables contain $\Psi^{*}, \operatorname{PAR}\left(0^{+}\right),\langle\mathrm{Chl}\rangle_{\text {tot }}$, and the product of these three quantities, namely $P$. There are two similarly arranged lookup tables, for either the case of uniform profiles or non uniform profiles. When using the tables, interpolations have to be made with the appropriate date, latitude, 

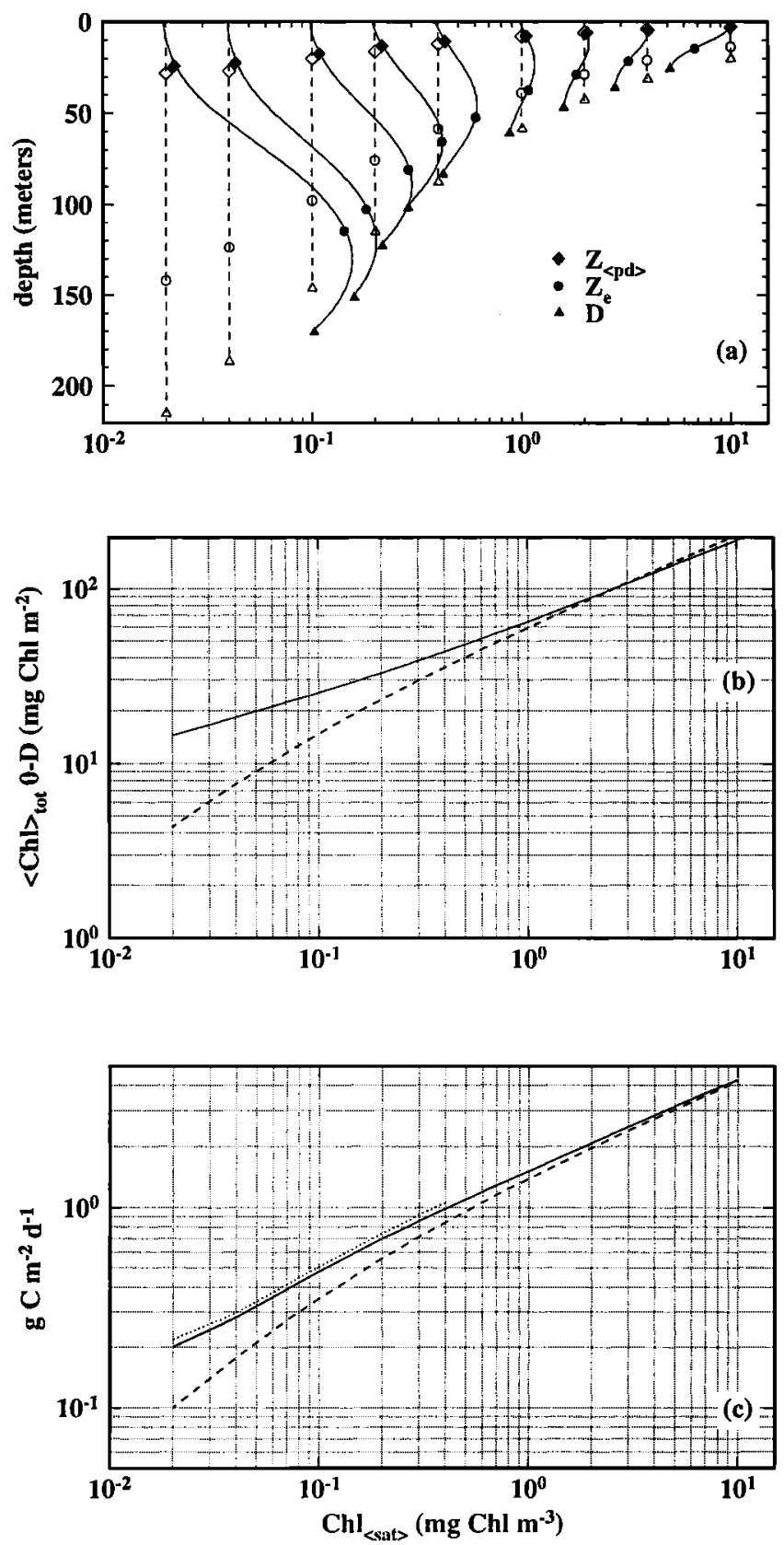

Figure 1. (a) Mean vertical profiles of chlorophyll (solid curves), as derived from (6) in Morel and Berthon [1989] for the nine upper layer chlorophyll concentrations, together with the corresponding uniform profiles (vertical dashed lines). Various depths are indicated : the "penetration depth" (i.e., the thickness of the layer "seen" by an ocean color remote sensor), $Z_{\varphi p d>}$, the euphotic depth, $Z_{e}$, and the depth of the productive layer, $D$. (b) columnintegrated chlorophyll content, as derived from (A10a) (uniform chlorophyll profiles, dashed curve), or (A10b) (nonuniform profiles, solid curve), as a function of the surface chlorophyll concentration. (c) Primary production calculated at the Equator and for the vernal equinox (clear sky), as a function of the surface chlorophyll concentration. The dashed and solid lines correspond to uniform or structured vertical chlorophyll profiles, respectively. The dotted line is obtained when the intensity of the deep chlorophyll maximum is doubled (see text). cloudiness, $\mathrm{Chl}_{<\text {sat }}$, and temperature values as entries (see Table 1). It has been numerically verified that, whatever the entry, linear interpolations provide $\Psi^{*}$ and $P$ values that are accurate within less than $2 \%$, if compared with the exact values (that is, computed for the specified conditions). Therefore there is no need for narrowing the increments when constructing the tables. Included in the tables are the $\operatorname{PAR}\left(0^{+}\right)$values, which correspond to each date-latitude-cloudiness triplet, the $\langle\mathrm{Chl}\rangle_{\text {tot }}$ values in correspondence with each $\mathrm{Chl}_{\text {<sat> }}$ entry in the table, the depth of the productive column $\mathrm{D}$, the cross section $\Psi^{*}$, and finally the resulting production which varies with temperature. Examples of contents of the lookup table are displayed (Figure 2) for two

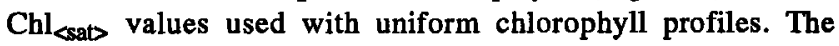
curves are always interrupted when latitude exceeds $76^{\circ} \mathrm{S}$ or as soon as the day length becomes shorter than 2 hours in high $\mathbf{N}$ and $S$ latitudes. As previously shown [Morel, 1991], $\Psi^{*}$ is almost insensitive to the chlorophyll concentration when the vertical distibution of algae is uniform, whereas it is highly dependent on the date, actually on irradiation and day length. This is illustrated in Figure 2, where the various curves of $\Psi^{*}$ as a function of $\operatorname{PAR}\left(0^{+}\right)$, each one for a given chlorophyll concentration, are almost confounded. As a consequence $\Psi^{*}$ remains steadily around $0.10 \mathrm{~m}^{2}\left(\mathrm{~g} \mathrm{Chl}^{-1}\right.$ near the Equator, and at $45^{\circ} \mathrm{N}$ or $\mathrm{S}$ varies from about 0.05 to $0.10 \mathrm{~m}^{2}(\mathrm{~g} \mathrm{Chl})^{-1}$ in summer and winter, respectively. At higher latitudes $\Psi^{*}$ experiences even wider variations, from about 0.03 in summer, up to $0.4 \mathrm{~m}^{2}(\mathrm{~g} \mathrm{Chl})^{-1}$. This maximum, however, occurs for the shortest days and for extremely reduced irradiation ( $<3 \%$ of that in summertime) and thus when production actually becomes insignificant. During these months, the vanishing production is realized with the best yield, that is, with a quantum yield value permanently close to its maximum $\varphi_{\mu, \max }$, leading to high $\Psi^{*}$ values. This numerical consequence of the production equation has admittedly never

Table 1. Entries and Content of Each Lookup Tables

\begin{tabular}{|c|c|c|}
\hline Entries & Description & $\mathbf{N}$ \\
\hline Dates & $\begin{array}{l}\text { The twenty-first } \\
\text { of each month }\end{array}$ & 12 \\
\hline Latitude & $\begin{array}{l}2.5^{\circ} \text { increment } \\
\text { from } 88.75^{\circ} \mathrm{N} \\
\text { to } 76.25^{\circ} \mathrm{S}\end{array}$ & 67 \\
\hline Cloudiness & $\begin{array}{l}\text { from } 0 \text { to } 1 \text { with } \\
0.1 \text { increment }\end{array}$ & 11 \\
\hline $\mathrm{Ch}_{\text {<sa }}$ & $\begin{array}{c}0.02,0.04,0.1,0.2 \\
0.4,1,2,4,10 \mathrm{mg} \mathrm{m}^{-3}\end{array}$ & 9 \\
\hline Water temperature & $\begin{array}{l}2^{\circ} \text { increment in the } \\
{\left[-10^{\circ},+40^{\circ} \mathrm{C}\right] \text { interval }}\end{array}$ & 26 \\
\hline Content & & unit of measure \\
\hline $\begin{array}{l}\text { D } \\
\langle\text { Chl }\rangle_{\text {tot }} \\
\operatorname{PAR}\left(0^{+}\right) \\
\Psi^{*} \\
\text { P }\end{array}$ & & $\begin{array}{r}\mathrm{m} \\
\mathrm{mg} \mathrm{Chl} \mathrm{m^{-2 }} \\
\mathrm{J} \mathrm{m}^{-2} \mathrm{~d}^{-1} \\
\mathrm{~m}^{2}\left(\mathrm{~g} \mathrm{Chl}^{-1}\right. \\
\mathrm{g} \mathrm{C} \mathrm{m}^{-2} \mathrm{~d}^{-1}\end{array}$ \\
\hline
\end{tabular}



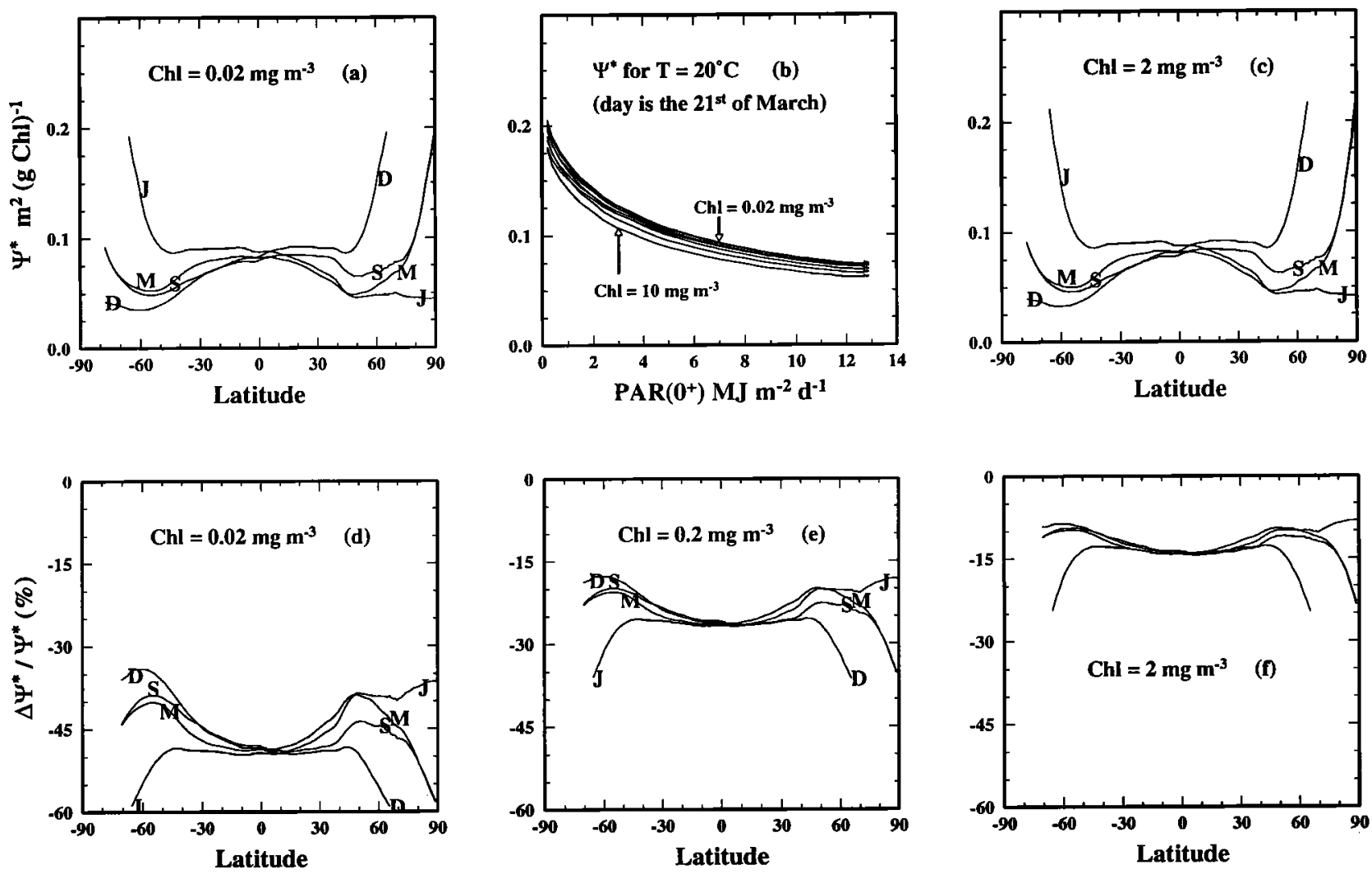

Figure 2. (a, c) examples of $\Psi^{*}$ values for two $\mathrm{Chl}_{\text {esat }}$ concentrations, as indicated. The chlorophyll vertical profile is uniform, the sky is clear, and the monthly temperatures are taken as the mean of the Levitus [1982] atlas for each latitude belt (bumps in the curves are due to temperature variations). The curves labeled M, J, S, D are for the twenty-first of March, June, September, and December, respectively. (b) Nine curves of $\Psi^{*}$ as a function of $\operatorname{PAR}\left(0^{+}\right)$ are shown (values are extracted from the tables for the date indicated and all latitudes); each one corresponds to a given chlorophyll concentration (see Table 1). (d, f) Relative changes in $\Psi^{*}$ with respect to the values shown in (a, c), under the same environmental conditions, when nonuniform vertical chlorophyll profiles $\left(\Psi^{*}{ }_{\text {nu }}\right)$ replace uniform profiles $\left(\Psi^{*}{ }_{u}\right)$. (e) as in (d, f), but with respect to $\Psi^{*}$ values computed for a uniform vertical chlorophyll profile, when $\mathrm{Chl}$ <sat> is $0.2 \mathrm{mg} \mathrm{m}^{-3}$. The relative changes, that is, $\left(\Psi^{*}{ }_{n u}-\Psi_{u}^{*}\right) / \Psi^{*}$, are expressed in percentage.

been verified through field experiments. In summer at high latitude, the low temperatures is the main factor which depress $\Psi^{*}$ and $P$.

The second lookup table deals with nonuniform chlorophyll profiles, and its contents are shown by comparison with those of the previous table. In Figure 2 (d, e, f) the relative differences (as percentage) in $\Psi^{*}$ for the same dates, latitudes, and $\mathrm{Chl}_{\text {<sat> }}$ concentrations than in Figure $2(a, c)$ (also for the same temperatures and clear skies) are plotted. With $\mathrm{Chl}_{<\text {sat }}=0.02 \mathrm{mg} \mathrm{m}^{-3}$, there is a DCM reaching a concentration of $0.16 \mathrm{mg} \mathrm{m}^{-3}$ at about $130 \mathrm{~m}$ (Figure 1a). This increase in biomass (by about a factor 3; Figure $1 \mathrm{~b}$ ) with respect to that of the uniform profile (with 0.02 $\mathrm{mg} \mathrm{\textrm {m } ^ { - 3 }}$ everywhere) is not compensated by a proportionate increase in production, because the additional production is realized within the deep chlorophyll maximum, where photosynthesis is strongly light-limited. Finally the difference is negative and $\Psi^{*}$ is steadily depressed, for instance by about $50 \%$ at the Equator. Nonetheless, these lowered $\Psi^{*}$ values are to be multiplied by much larger $\langle\mathrm{Chl}\rangle_{\text {tot }}$ values when using ( 1 ) and (1b), so that the resulting production is approximately doubled (Figure 1c). Larger and more variable differences $(-35,-60 \%)$ would occur at high latitude ( $50^{\circ} \mathrm{N}$ or S), except that such stratified situations leading to the maintenance of a DCM are not expected there.

With a higher $\mathrm{Chl}_{<\text {sat }}$ concentration $\left(2 \mathrm{mg} \mathrm{m}^{-3}\right)$, the situation is different. The corresponding mean chlorophyll profile exhibits a weak maximum close to the surface (Figure 1a), so that more biomass lies within the highly lighted layer. Conversely, the lower portion of the structured profile shows a biomass slightly lower compared to the uniform distribution. The difference in $\Psi^{*}$, still negative, is only of about $15 \%$. Because the integrater biomass is about the same as in the case of uniform distribution (Figure 1b), $P$ is slightly decreased (Figure 1c). For the intermediate situation $\left(\mathrm{Chl}_{<\mathrm{sat>}} \sim 0.2 \mathrm{mg} \mathrm{m}^{-3}\right) \Psi^{*}$ would be depressed by about $25 \%$ within the entire $50^{\circ} \mathrm{N}-\mathrm{S}$ belt : in this case the nonuniform biomass exceeds the uniformly distributed biomass (by about $\mathbf{4 0}$ $\%$, Figure $1 \mathrm{~b}$ ), in such a way that the resulting column production is moderately enhanced (by $25 \%$, Figure $1 c$ ).

The response to the shape of the vertical pigment profile is briefly examined in complement to the above comparison between the two lookup tables (with and without DCM). It must be emphasized that changing physiology (as it will be made below) only affects the resulting $\Psi^{*}$ value and thus directly modifies the computed production $P$. In contrast, changing the 
vertical distribution of algae for a given $\mathrm{Chl}_{<\text {sat> }}$ value changes both $\Psi^{*}$ and $\langle\mathrm{Chl}\rangle_{\text {tot }}$, with a more complex impact on $P$. When producing the second $\Psi^{*}$ lookup table, the structured profiles adopted were mean, statistically derived, profiles; it is thus possible that the actual deep maximum magnitude exceeds the mean value. A test can be made by doubling the intensity of the Gaussian peak, at least when it is distinctly marked (i.e., when - $\mathrm{Chl}_{<s a t>}$ is low enough). For instance, with $\mathrm{Chl}_{<s a t>}=0.02 \mathrm{mg} \mathrm{Chl}$ $\mathrm{m}^{-3}, \Psi^{*}$ is again depressed by $20-30 \%$ with respect to its value for the mean, structured, profile; in the meanwhile $\langle\mathrm{Chl}\rangle_{\text {tot }}$ is increased by about $30 \%$ and $D$ reduced by $17 \mathrm{~m}$. These changes in $\Psi^{*}$ and $\langle\mathrm{Chl}\rangle_{\text {tot }}$ result only in a small rise of primary production (Figure 1c).

\section{Sensitivity Studies}

The cross section for photosynthesis and per unit of chlorophyll, $\Psi^{*}$, is the relevant quantity for sensitivity studies, as it is fundamental (even if still dependent on the environmental conditions). Variations in this bulk efficiency parameter can be analyzed in a meaningful way, while those in the realized primary production are to the first-order controlled by the biomass itself and the available radiation, the transfer function being $\Psi^{*}$.

If the linear impact of any change in the value assigned to $a^{*}{ }_{\text {max }}$ or $\varphi_{\mu, \max }$ is straightforwardly assessed, it is not the case for all the other quantities appearing inside the production integral (A9). The non linear response to change in parameters or parameterizations can only be estimated through sensitivity studies, separately presented below. They are made in reference to the standard case (lookup tables with uniform chlorophyll profiles, unless otherwise specified) with the same parameter values except for the parameter under study. These studies deal first with the absorption capabilities and then with the transfer of absorbed energy (the structure of the $f(x)$ function and parameters herein included).

Changing the Shape of the Algal Absorption Spectrum. Given the available radiation PAR, the evaluation of the usable radiation (PUR in (A3)) depends on the choice of an absorbability spectrum $A^{*}(\lambda)(A 2)$. A typical absorption spectrum for diatoms, obtained by averaging the spectra of Chaetoceros curvisetum and Chaetoceros lauderi [Bricaud et al., 1988], and Skeletonema costatum [Bricaud and Morel, 1986] is also displayed in Figure 3, as well as the absorption spectra of Synechococcus (strain WH 7803) and Prochlorococcus marinus taken from Morel et al. [1993]. Diatoms can be seen as representative species of eutrophic waters, while prochlorophytes together with cyanobacteria may become dominant in an oligotrophic environment. With such differing absorption spectra, these three phytoplanktonic groups provide a good representation of the maximal variations to be expected. Since the absorption spectrum for diatoms and the standard spectrum are very close, the comparison is useless and the tests are made only by considering the contrasted Synechococcus and Prochlorococcus spectra.

The effects on $\Psi^{*}$ (Figure 4) can easily be anticipated from the spectral characteristics of the species. In the case of cyanobacteria, an enhanced absorption capability in the green part of the spectrum significantly increases $\Psi^{*}$ in "green" waters, (i.e., where the chlorophyll concentration is $2 \mathrm{mg} \mathrm{m}^{-3}$ ) and unsignificantly in "blue", low chlorophyll, waters. In exclusive presence of prochlorophytes, with a lower absorption capacity, $\Psi^{*}$

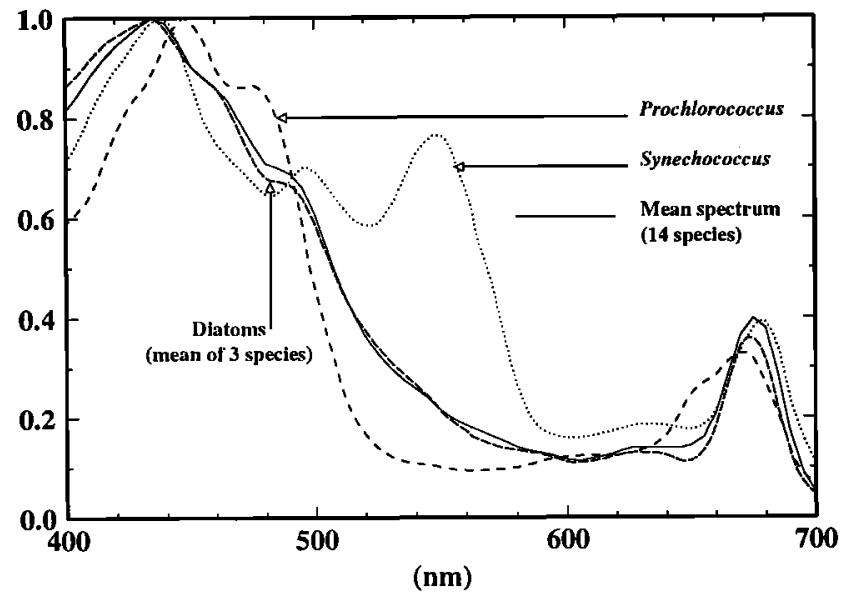

Figure 3. The dimensionless function $A^{*}(\lambda)$ (A2), describing the shape of the algal absorption spectra of various photosynthesizing algal species or groups.

is slightly and unsignificantly depressed (this effect would not be negligible only in the unrealistic case of green waters with extremely high concentration of pure prochlorophytes). It must be noted that the present sensitivity study, like the standard computation, is made under the assumption of a perfect efficiency in the energy transfer by the various pigments. The issue of photoprotective pigments is not at the PUR evaluation level. If envisaged, this problem is to be approached by reintroducing a wavelength dependency into $\varphi_{\mu}$ (as formally written in (A1)), and thus by abandoning the simplifying assumption made here of an action spectrum coinciding with the absorption spectrum.

Changing the Photosynthesis Light Response 1. Maximum Photosynthetic Rate. The value given to the "scaling irradiance", KPUR (A5), is crucial as it sizes the magnitude of the $\mathrm{P}^{\mathrm{B}}$ versus $E$ curve and fixes the level of its plateau. This curve is implicitely contained in (A6a) or (A6b). By using the KPUR, $\mathrm{a}^{*}$ max , and $\varphi_{\mu, \max }$ values selected for the standard computation (Appendix D), the maximum rate at $20^{\circ} \mathrm{C}$ is (A7)

$$
\mathrm{P}_{\text {max }}^{\mathrm{B}}=4.6 \mathrm{~g} \mathrm{C}(\mathrm{g} \mathrm{Chl})^{-1} \mathrm{~h}^{-1}
$$

According to (A8), $\mathrm{P}^{\mathrm{B}}$ max is allowed to vary between approximately 1.4 and $8 \mathrm{~g} \mathrm{C}\left(\mathrm{g} \mathrm{Chl}^{-1} \mathrm{~h}^{-1}\right.$, when temperature increases from $1^{\circ}$ to $29^{\circ} \mathrm{C}$. Such a range agrees with most of the observations at sea [e.g., Ryther and Yentsch, 1957; Kirk, 1983; Cullen, 1990; Cullen et al., 1992], so that the standard value given to KPUR certainly represents at least a realistic mean. For a long time, however, it has been acknowledged that adaptative or genetic variability in natural populations results in wide changes in $\mathrm{P}^{\mathrm{B}}{ }_{\max }$ [see Geider, 1993, and references therein]. As a consequence of light/shade adaptation in vertically stable waters, the maximum rate is often found to be positively correlated to the in situ mean irradiance level [Schofield et al., 1993; Cullen, 1990] and therefore it decreases with increasing depth. Furthermore, the physiological mechanisms involved in algal photoadaptation have been thoroughly studied and substantiated [Sukenik et al., 1987]. It is worth recalling that such variability, or regular vertical trends of $\mathbf{P}_{\text {max }}^{\mathrm{B}}$, are different from, and superimposed onto, its regular temperature-dependent evolution (already accounted for).

For the present trials, it will simply be assumed that the above $\mathbf{P}_{\text {max }}^{\mathbf{B}}$ value could be halved or doubled, by multiplying KPUR by 

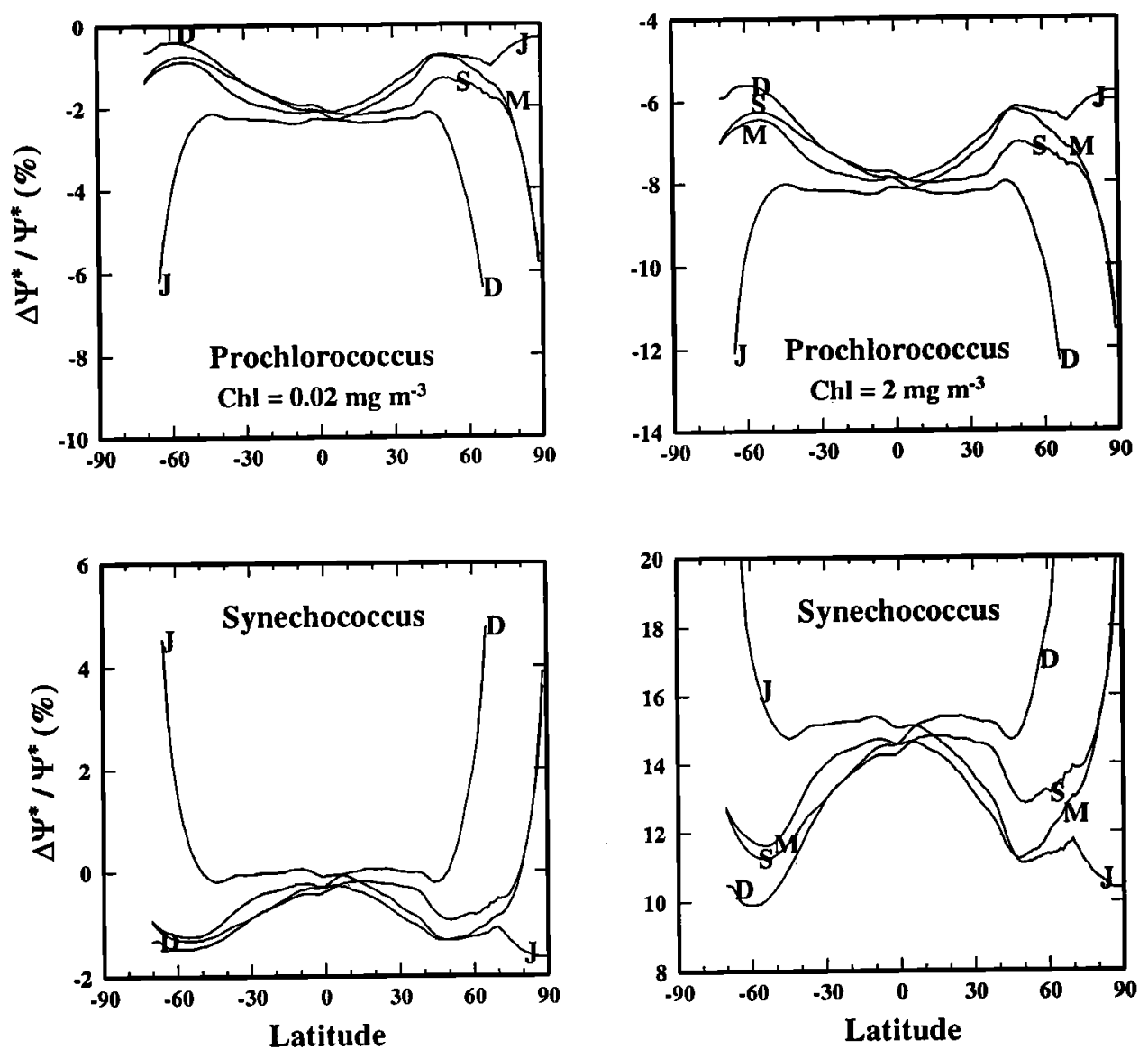

Figure 4. Relative changes in $\Psi^{*}\left(\Delta \Psi^{*} / \Psi^{*}\right.$, as percentage), with respect to the "standard" $\Psi^{*}$ values (i.e., computed under the conditions indicated for Figure $2(a, c)$ ), when the absorption spectrum of algae is that of Prochlorococcus or that of Synechococcus, and for the chlorophyll concentrations indicated.

0.5 or 2 . The maximum rate, $\mathrm{P}_{\text {max }}$, actually is directly governed by KPUR to the extent that the initial slope of the $\mathrm{P}^{\mathrm{B}}$ versus $\mathrm{E}$ curve is unchanged (when $\mathrm{a}^{*}{ }_{\max }$ and $\varphi_{\mu, \max }$ are kept constant in A7). The results in Figure 5 are displayed as relative changes in $\Psi^{*}$ with respect to the $\Psi^{*}$ values computed using the standard KPUR value, and for the same dates and latitudes. As expected, the responses of $\Psi^{*}$ to changes in $\mathrm{P}^{\mathrm{B}}$ max are not linear and this nonlinear effect is depending on the radiation availability. At moderate latitudes for instance, say between $40^{\circ} \mathrm{N}$ and $40^{\circ} \mathrm{S}$, and for all seasons, $\Psi^{*}$ is reduced (increased) by a factor $0.7(1.4)$ when KPUR is changed by a factor 0.5 (2), respectively. At higher latitudes, the relative change in $\Psi^{*}$ becomes dependent on the season. In winter and at low irradiance levels, photosynthesis is almost permanently light-limited within the entire productive column and the primary production is essentially realized along the initial, ascending, portion of the $\mathrm{P}^{\mathrm{B}}$ versus $\mathrm{E}$ curve. Thence $\Psi^{*}$ tends to be unsensitive to the actual $\mathrm{P}^{\mathrm{B}}{ }_{\max }$ level and, as a consequence, $\Psi^{*}$ is modified only by a factor of about $0.8-0.9$ or 1-1.2 in response to a halving or a doubling of $\mathrm{P}^{\mathrm{B}}{ }_{\max }$. In contrast, when day length and irradiance are near their maximum for these high latitudes, production is mainly realized and maintained at its maximum rate. Because the irradiance value corresponding to the onset of saturation is lowered by low temperature, the maximum rate is easily reached in summertime. In such circumstances $\Psi^{*}$ and $P$ are almost linearly related to the value imposed to $P^{B}{ }_{\text {max }} \cdot A$ parameterization allowing $\mathrm{P}^{\mathrm{B}}{ }_{\max }$ to be dependent upon the mean irradiance level and equivalently upon depth would be more realistic. Such a simulation, feasible case by case when the depth dependence of $\mathrm{P}^{\mathrm{B}}{ }_{\max }$ has been experimentally established, cannot be easily generalized in the frame of global predictions.

Changing the Photosynthesis Light Response 2. Light Inhibition. Computations are run by using (A6b) instead of (A6a), and by keeping the same conditions as before. The relative changes in $\Psi^{*}$ are displayed in Figure 6 . The suppression of inhibition obviously leads always to positive variations, by 2 to $4 \%$ in tropical and temperate ocean, and by 0 to $5 \%$ at high latitude, in winter and summer, respectively. According to the parameterization adopted, the effect of inhibition actually cannot be disconnected from the temperature effect. The decreasing KPUR value at low temperature (A8) and the correlative decrease in $\mathrm{PB}^{\mathrm{B}}{ }_{\max }$ (as well as the shortening of the plateau of the $\mathrm{P}^{\mathrm{B}}$ versus $E$ curve) entail an enhancement of the inhibitory effect at constant $\beta$ value. Therefore the difference is maximal in summer and lessens during the short days period with low insolation, because the $\mathrm{P}_{\max }^{\mathrm{B}}$ values, and a fortiori the photoinhibited regime, are never reached. For the sake of completness, it must be noticed 

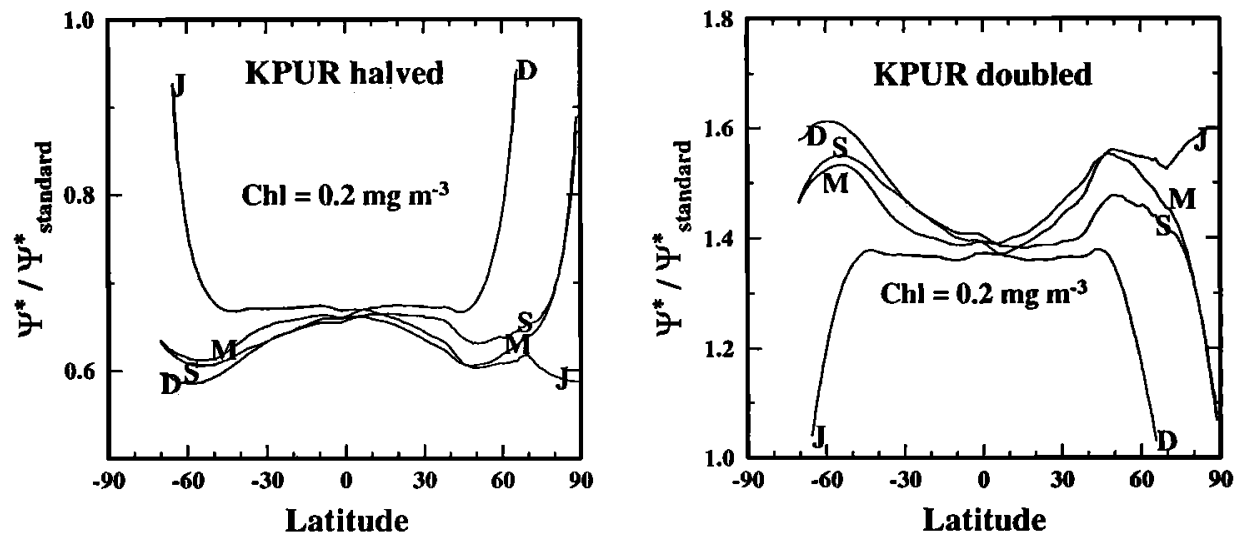

Figure 5. Ratio of the $\Psi^{*}$ values obtained when KPUR is halved or doubled to the "standard" $\Psi^{*}$ values (results are nearly identical when $\mathrm{Chl}=0.02$ and $2 \mathrm{mg} \mathrm{m}^{-3}$ ).

that another way of modifying the shape of the $P$ versus $E$ curve would be to use (A6c) instead of (A6b). This possible choice actually leads to insignificant changes of the computed production.

Accounting for the Presence of Pheopigments. In (1), only "active" chlorophyll is involved, while the satellite-derived pigment concentration is generally quantified as (chlorophyll $a+$ pheophytin $a$ ) concentration. This merging originates from the impossibility in discriminating between the optical effects of the active form (chlorophyll) and of its degraded form (pheophytin). For the same reason, the biooptical model used to predict the downward irradiance profile and the depth of the productive layer makes no difference between the two forms. Nevertheless, the $\Psi^{*}$ value remains unchanged in presence of pheopigments [see discussion by Morel, 1991]. In practice, the satellite "pigment" concentration (without any correction) must be used to select the $\Psi^{*}$ value and obtain P. If information exists or assumptions can be made (see below) concerning the ratio $\rho$, equal to $\mathrm{Chl} a /$ (Chl

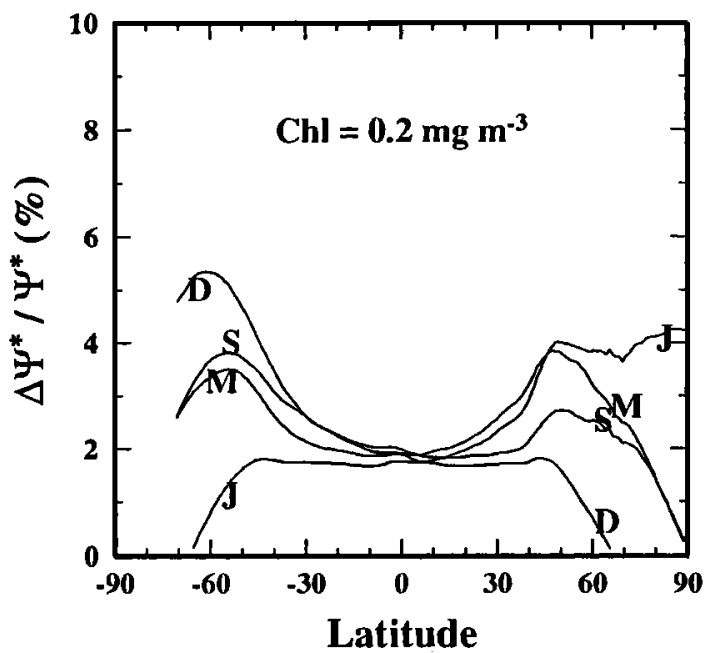

Figure 6. Relative changes in $\Psi^{*}\left(\Delta \Psi^{*} / \Psi^{*}\right.$, as percentage), with respect to the "standard" $\Psi^{*}$ values, when the $\beta$ parameter is set to 0 (no photoinhibition; equation (A6b)); the results are nearly identical when $\mathrm{Chl}=0.02$ and $2 \mathrm{mg} \mathrm{m}^{-3}$. $a+$ Pheo $a$ ), the production values can be straightforwardly corrected, just by applying $\rho(<1)$ as a multiplier.

Indeed, there is a considerable debate about the historical determinations of $\rho$ which were derived from simple fluorimetric measurements before and after acidification [Yentsch and Menzel, 1963]. This method has been extensively applied when developing the CZCS algorithms, and has led to the units used for the satellite-derived "chlorophyllous pigment concentration", expressed as the sum (Chl $a+$ Pheo $a)$ and in units milligrams per cubic meter. It is now acknowledged [e.g., Vernet and Lorenzen, 1987] that $\mathrm{Chl} b$ may interfere and produces either an artifactual detection or an overestimation of the pheophytin concentration. With a notable proportion of Chl $b$, in oligotrophic waters in particular, the historical $\rho$ values are highly questionable [Herbland, 1988; Ondrusek et al., 1991]. Recent measurements via High Pressure Liquid Chromatography (HPLC) tend to prove that pheopigments are practically absent in many oceanic areas [e.g., Claustre and Marty, 1995]. Because the $\rho$ ratio has a direct impact on the computed production, the recent progress in pigment analysis will certainly modify some of the previous envisions.

\section{Discussion and Conclusions}

Summarizing the results of the sensitivity studies, it can be concluded that the parameterizations or parameters, for which assumptions and standard sets of values were needed, can be arranged in increasing order of their impact on $\Psi^{*}$ and then on $P$ as follows (1) The shape of the absorption spectrum of algae, $\mathrm{A}^{*}(\lambda)$, in correspondance with a change in dominant species, has a minor effect. (2) A similar conclusion can be drawn with respect to inhibition. (3) Ignoring or accounting for the nonuniformity of the vertical algal distribution entails more serious deviations in $\Psi^{*}$. It must be pointed out that when a deep chlorophyll maximum is present, $\Psi^{*}$ decreases relatively to its value for a uniform pigment distribution. This decrease in $\Psi^{*}$, however, is more than compensated by the increase in $\langle\mathrm{Chl}\rangle$ tot, so that, when using (1), $P$ is definitely higher than if computed for a uniform profile. This increase is significant for all oligotrophic tropical zones. (4) More severe is the influence of the scaling irradiance, 
which at any temperature governs the value of the saturated rate of carbon incorporation $\mathrm{P}^{\mathrm{B}}{ }_{\text {max }}$. The variation in $\Psi^{*}$ is not linearly related to that in $\mathrm{P}^{\mathrm{B}}{ }_{\text {max }}$. Nonetheless, a linear approximation can be used when a small change in $\mathrm{P}^{\mathrm{B}}{ }_{\max }$ (with respect to its standard value) is envisaged. If, according to future available measurements, a more considerable change in $\mathrm{P}^{\mathrm{B}}{ }_{\max }$ seems necessary, the use of the present lookup tables is not precluded. By virtue of (A7) and (A8), $\mathrm{P}^{\mathrm{B}}$ max and $T$ are unequivocally related, so that it is always possible to select in the table the appropriate $\mathrm{PB}_{\max }$ value by changing the temperature (with respect to the actual one, see Appendix A). Finally, (5) The bulk maximum efficiency, expressed by the product $a^{*}{ }_{\max } \varphi_{\mu, \max }$, and the pigment activity index $\rho$ are crucial parameters. Fortunately (from a purely computational viewpoint), any change in their values does not involve more than a final linear adjustment of the computed production. Unfortunately (from a practical viewpoint), the actual changes in these parameters are far from being well documented in the real world. These conclusive remarks (4 and 5) meet the recommendations made by Platt and Sathyendranath [1988] to "measure the frequency distributions of the photosynthesis parameters and their seasonal variations", and their suggestion of establishing biogeographical provinces based on the knowledge of the specific physiological parameters of their algal populations.

Finally, it is worth recalling that the rather simple model operated here to produce the lookup tables does not take into consideration the temperature variations inside the productive layer and also ignores the possible vertical variations of the physiological characteristics. For instance, a variable $\mathrm{P}_{\text {max }}^{\mathrm{B}}$ along the vertical axis (independent from that due to a temperature gradient), which would reflect a photoacclimation, is not accounted for. The same remark holds true for $\varphi_{\mu, \max }$ and ${ }^{*}{ }_{\max }$, even if they are known to vary spatially and may also change along the vertical. Any vertical trend can easily be accomodated in alternative versions of the code (used, for instance, in conjunction with observations at sea). With the aim of producing tables of general applicability, such improved versions presently remain impracticable or risky, because general parameterizations of ubiquitous validity for these vertical trends are still lacking.

Ideally, the present method must apply to chlorophyll maps made available on a daily basis, so that the computed primary production is for the day in question. Other processes, essentially grazing, sinking, and decay, concurrently with physical conditions (PAR, vertical mixing) govern the further biomass evolution. They are not taken into account. In summary, the present technique is a diagnostic approach and cannot say more than what it is intended for. Practically, a daily general information about the chlorophyll distribution is out of reach because of cloud occurrence and instrumental limitations (swath, orbit repeat cycle). Therefore a satellite chlorophyll value will have to be considered as valid (and constant) for a certain period when deriving the primary production. This period may even extend up to that adopted when compositing the satellite imagery (e.g. 1 month with CZCS global imagery). Hopefully it will be reduced with the simultaneous deployement of several ocean color sensors in the future. In parallel, the environmental conditions (temperature, cloudiness) have also to be cumulated (or averaged) over the same period. Finally, with respect to an ideal use of the model on a daily basis, approximations are inevitable. Their effects, out of the scope of the present study, require specific studies.

\section{Appendix A : Basic Equations and Their Practical Utilization}

The core of the parameterization of the production - irradiance relationship is the local (depth, $z$ ) and instantaneous (time, $t$ ) growth rate equation [Bannister, 1974 ; Kiefer and Mitchell, 1983] written for a monochromatic radiation. It accounts for the two sequential processes; namely, for the absorption of radiant energy and then for the transformation of captured energy into photosynthetic assimilate, expressed as mass of organic carbon fixed per unit of time and volume, $P\left(\mathrm{~g} \mathrm{C} \mathrm{m}^{-3} \mathrm{~s}^{-1}\right)$. This equation reads

$$
\mathrm{P}(z, t, \lambda)=12 \operatorname{Chl}(z, t) \mathrm{a}^{*}(z, t, \lambda) \operatorname{PAR}(z, t, \lambda) \varphi_{\mu}(z, t, \lambda)
$$

In this equation, $\mathrm{a}^{*}$ is the chlorophyll specific absorption of algae, expressed as $\mathrm{m}^{2}$ ( $\left.\mathrm{g} \mathrm{Chl}\right)^{-1}$, so that the product of the first three terms represents the absorbed energy, provided that PAR is scalar irradiance ; $\varphi_{\mu}$ is the yield of the transformation, and is expressed as a "quantum yield for growth" when PAR is expressed in mol quanta $\mathrm{m}^{-2} \mathrm{~s}^{-1}$ and when the net amount of carbon fixed is in mol $\mathrm{C}$. The latter is transformed into mass by using the carbon molar weight $\left(12 \mathrm{~g} \mathrm{~mol}^{-1}\right)$. The subsequent computation consists of integrating the above equation with respect to wavelength and time to obtain $P(z)$, and then with respect to depth to obtain P. By combining $P$ with $\operatorname{PAR}\left(0^{+}\right)$and $\langle\mathrm{Chl}\rangle_{\text {tot }}$ (equations (3) and (4)), $\Psi^{*}$ is straightforwardly obtained (equations (1) and (1b) in introduction). $J_{C}(1 b)$ is given the value $39 \mathrm{~kJ}\left(\mathrm{~g} \mathrm{C}^{-1}\right.$, adopted from Platt [1969]. This number actually has no importance, provided that the same value is used when reverting (1) and (1b), that is, when using $\Psi^{*}$ to derive $P$.

The diagnostic approach represented by (A1) can only be operated when all information is available. However, it is never the case when using satellite data. In such a perspective, global scale and climatological fields are the ultimate goal, although fully (spatial, temporal) documented database (in particular for the physiological parameters involved) do not exist. As a consequence, some simplifying hypotheses must be adopted in the present approach, and choices have to be made, which are summarized below.

(1) The time dependence of $a^{*}, \varphi_{\mu}$ and of the chlorophyll vertical profile are abandoned. (2) The depth dependency of absorption is also suppressed and the wavelength dependency is, for computational convenience, expressed as

$$
a^{*}(\lambda)=a^{*} \max A^{*}(\lambda)
$$

where $\mathrm{a}_{\text {max }}^{*}$ is the maximal value found within the chlorophyll specific absorption spectrum (generally near $435 \mathrm{~nm}$ ) and $A^{*}(\lambda)$ is a dimensionless function defined in the interval $(1,0)$ which describes the shape of the algal absorption spectrum. The "standard" $A^{*}(\lambda)$ function, taken by Morel [1991], is adopted (shown in Figure 3, together with some other typical functions, used in sensitivity studies). The adoption of a mean standard spectral shape and of a unique $a^{*}{ }_{\text {max }}$ is necessary, albeit simplifying. It is known that due to various pigmentations and packaging effect, the $a^{*}(\lambda)$ spectrum (shape and magnitude) is changing with algal species and populations. The $A^{*}(\lambda)$ function allows the photosynthetically usable radiation [Morel, 1978] to be computed as 


$$
\operatorname{PUR}(z, t)=\int_{400}^{700} \operatorname{PAR}(z, t, \lambda) \mathrm{A}^{*}(\lambda) \mathrm{d} \lambda
$$

The local and instantaneous value, $\operatorname{PUR}(z, t)$, represents that fraction of available energy which can potentially be absorbed by algae. Like PAR, it is expressed as quanta $\mathrm{m}^{-2} \mathrm{~s}^{-1}$ and also based on scalar irradiance. What is actually absorbed depends on the local abundance of algae, and is expressed by the product

$$
a_{\max }^{*} \operatorname{PUR}(z, t) \operatorname{Chl}(z)
$$

(3) It is assumed that the action spectrum of photosynthesis coincides with that of absorption; in other words, the quantum yield for growth is considered as independent of wavelength. Lower efficiency of some pigments in transferring absorbed energy could operationally be accounted for by an appropriate choice of a value for $\varphi_{\mu, \max }$ (see below). (4) It is also assumed that $\varphi_{\mu, \max }$ is independent of depth, so that the product $\mathrm{a}^{*}{ }_{\max } \varphi_{\mu, \max }\left(=\alpha^{\prime}\right.$, Morel et al., [1987]) is constant (see Appendix D). (5) The quantum yield for net growth $\varphi_{\mu}$ is also scaled with respect to its maximal value $\varphi_{\mu, \max }$, attained at vanishing irradiance, according to

$$
\varphi_{\mu}(\mathrm{x})=\varphi_{\mu, \max } \mathrm{f}(\mathrm{x})
$$

the dimensionless function $f(x)$ is defined on $(1,0)$, and $x$ is a dimensionless descriptor of usable irradiance, defined as

$$
\mathbf{x}=\text { PUR / KPUR }
$$

where KPUR is a scaling irradiance (see below). The function $f(x)$ describes the light-photosynthesis response via the slope of the secant of the so-called " $\mathrm{P}^{B}$ versus $E^{2}$ curve, when the irradiance $E$ is quantified in terms of PUR (and not as usual in terms of PAR). The classical parameters of the $P^{B}$ versus $E$ curve (namely the chlorophyll specific initial slope and the maximal production, $\alpha^{B}$ and $\mathrm{P}_{\text {max }}^{\mathrm{B}}$, respectively) are directly related to $\mathrm{a}_{\text {max }}{ }, \varphi_{\mu, \max }$ and KPUR (see (22b) and (22c) in Morel [1991] and (A7) below). It is assumed that KPUR is independent of depth. (6) For the present computations, the photosynthesis-light curve adopted as the standard one is that introduced by Platt et al. [1980]. According to the above dimensionless formulation, this function is expressed as

$$
f(x)=x^{-1}\left(1-e^{-x}\right) e^{-\beta x}
$$

where $\beta$ accounts for inhibition at high irradiance. If inhibition is discarded (as made in sensitivity analysis), this equation becomes

$$
f(x)=x^{-1}\left(1-e^{-x}\right)
$$

and thus follows the Webb et al. [1974] model, or the mechanistic target theory [Dubinsky et al., 1986]. Another mathematic representation can be adopted, derived from the Jassby and Platt [1976] formulation and based on a byperbolic tangent function

$$
f(x)=x^{-1} \tanh (x)
$$

Apart from an enhanced convexity the shape of the $f(x)$ curve is very close to that provided by (A6b).

The scaling irradiance KPUR is nothing else than $\mathrm{E}_{\mathrm{k}}$, the saturation onset parameter defined by Talling [1957], provided that $P$ is plotted as a function of the absorbed radiation and not (as usual) as a function of available radiant energy. Therefore KPUR also determines the maximal value, $\mathrm{P}^{\mathrm{B}}{ }_{\max }$ of the $\mathrm{P}^{\mathrm{B}}$ versus $\mathrm{E}$ curve according to (22b) by Morel [1991].

$$
\mathrm{P}_{\max }^{\mathrm{B}}=12 \mathrm{a}^{*} \max \varphi_{\mu, \max }[\mathrm{xf}(\mathrm{x})]_{\max } \text { KPUR }
$$

Once a mathematical expression has been adopted for the $f(x)$ function, the bracketed product above experiences one maximum when the dimensionless descriptor of usable irradiance, $x$, goes from 0 to $\infty$. With (A6a), this maximum is equal to 0.945 (at $x=$ 4.615 if $\beta$ is 0.01 ), or equal to 1 (at $x=\infty$ ) with (A6b) (see Table 1 by Morel [1991]).

(7) The temperature effect upon growth is accounted for by allowing KPUR to be dependent on temperature with a $Q_{10}$ (increase in growth rate per $10^{\circ} \mathrm{C}$ rise) equal to 1.88 as suggested by Eppley [1972], thus

$$
\operatorname{KPUR}(T)=\operatorname{KPUR}\left(20^{\circ}\right) 1.065^{\left(T-20^{\circ}\right)}
$$

By combining with (A7), it follows that the maximum, light-independent, photosynthetic rate is regulated only by temperature according to

$$
\mathbf{P}_{\max }^{\mathrm{B}}(T)=\mathbf{P}_{\max }^{\mathrm{B}}\left(20^{\circ}\right) 1.065^{\left(T-20^{\circ}\right)}
$$

and changes by a factor 6.6 to 1 when $T$ decreases from $30^{\circ}$ to $0^{\circ} \mathrm{C}$. If such a Vant'Hoff law provides an adequate description of the immediate temperature effect for algae in culture when transferred from their growing temperature to other (lower or greater) temperatures, its validity has been questioned if applied to algae growing in nature over a wide range of temperature (see discussion by Kirk [1983]). Some thermal adaptation or optimization may occur via a change in the enzyme pool [Yentsch, 1974]. Such an adaptation strategy, for cold water species for instance, would consist in growing faster than temperate species would do if transferred at the same low temperature. Such a deviation from Eppley's equation does not seem to occur, at least in a significant way [see e.g., Gilstad and Sakshaug, 1990].

By reassembling the above terms according to (A1) and then integrating, the daily column production is computed according to

$$
\begin{aligned}
P=12 & a_{\max }^{*} \\
& \int_{\mu}^{L D} \int_{0}^{L} \int_{400} \operatorname{Chl}(z) \operatorname{PUR}(z, t, \lambda) \mathrm{f}(\mathrm{x}(z, t)) \mathrm{d} \lambda \mathrm{d} z \mathrm{~d} t
\end{aligned}
$$

Note that $x$, which, in a dimensionless fashion, reflects the instantaneous and local radiant energy ((A5) and (A3)), is accordingly a function of time and depth.

The above equations deserve some additional comments. In (A7), it appears that the maximum photosynthetic rate $\mathrm{P}^{\mathrm{B}}$ max depends on the algal absorption (through $\mathrm{a}^{*}$ max $)$. If it is numerically true in the frame of the approach used here, it is erroneous from a purely physiological viewpoint. The light-saturated photosynthesis level obviously is independent of the absorption capacity, in contrast to the onset of this regime. This contradiction is only apparent. Equation (A7) provides the value of $\mathrm{P}^{\mathrm{B}}{ }_{\max }$ once the initial slope of the photosynthesis-light curve is fixed (through the product $\alpha^{\prime}=\mathrm{a}^{*}{ }_{\text {max }} \Phi_{\mu, \text { max }}$ ), the saturation onset parameter is fixed (through KPUR), as well as the shape of the curve (the $f(x)$ function). The sensitivity analysis carried out in this work is made on the hypothesis of changing $\mathbf{P}^{B}{ }_{\max }$ only by varying KPUR. In a natural environment, other, more intricated, changes affect simultaneously the two independent physiological parameters. Therefore the statement made in different places that $P$ is linearly related to the product $\mathrm{a}^{*}{ }_{\max } \varphi_{\mu, \max }$ (which is mathematically irrefutable, according to (A9)) can be disputed in specific situations. For instance, changing $\mathrm{a}^{*} \max \varphi_{\mu, \max }$ under the constraint of maintaining $\mathbf{P}_{\max }^{\mathbf{B}}$ constant implies adjusting KPUR 
accordingly. Therefore $x(A 5)$ and $f(x)$, inside the integral, are modified. Such situations, to be considered when using the model in conjunction with in situ data and full information about the algal physiology, cannot be considered in the standard computation required for the production of the lookup tables.

The temperature range adopted for the systematic computations $\left(-10^{\circ} \mathrm{C},+40^{\circ} \mathrm{C}\right.$, see Table 1$)$ by far exceeds the normal oceanic range and has been considered only for numerical convenience. Indeed $T$ reacts on the computed production through (A7), that is, via the $\mathrm{P}^{\mathrm{B}}{ }_{\max }$ value. Therefore, when using the lookup tables, temperature can be changed with respect to its actual value in order to modify $\mathrm{P}_{\text {max }}^{\mathrm{B}}$ with respect to its standard value. A potential user can disagree with the choice made in the model, or according to measurements other values of $\mathrm{P}^{\mathrm{B}}$ max may appear as more appropriate. If, for instance, $\mathrm{P}^{\mathrm{B}} \max$ as measured in a water body at $0^{\circ} \mathrm{C}$ turns out to be $1.0 \mathrm{~g} \mathrm{C}\left(\mathrm{g} \mathrm{Chl}^{-1} \mathrm{~h}^{-1}\right.$, whereas at this temperature the standard value is $1.3 \mathrm{~g} \mathrm{C}\left(\mathrm{gChl}^{-1} \mathrm{~h}^{-1}\right.$, entering into the table with $T=-4.16^{\circ} \mathrm{C}$ will restore $\mathrm{P}^{\mathrm{B}}{ }_{\max }$ at the desired level. In correspondance with the $-10^{\circ} \mathrm{C},+40^{\circ} \mathrm{C}$ range considered here, accessible values of $\mathrm{P}^{\mathrm{B}}$ max are between 0.69 and $16.2 \mathrm{~g} \mathrm{C}$ (g Chl $)^{-1} \mathbf{h}^{-1}$.

\section{Appendix B : Deriving $<\mathrm{Chl}>_{\text {tot }}$ From $\mathrm{Ch}_{\text {sat }}$}

For a given $\mathrm{Chl}_{<s a t>}$ value, the corresponding vertical $\mathrm{Chl}(z)$ profile is either derived from (6) by Morel and Berthon [1989] or assumed to be uniform. The structured profile or the uniform profile are introduced in the model of irradiance propagation [Morel, 1988] in view of determining the depth of the 0.1\% PAR level, denoted D. By integrating the $\mathrm{Chl}(z)$ profile down to $\mathrm{D}$, the column-integrated content $\langle\mathrm{Ch}\rangle_{\text {tot }}$ is obtained. In order to avoid repeating such computations, the two relationships between $<\mathrm{Chl}\rangle_{\text {tot }}$ and $\mathrm{Chl}_{<\text {sat }}$ have been fitted to the following polynomial expressions

$$
\begin{aligned}
Y= & 1.774+0.557 \mathrm{X}-2.91510^{-2} \mathrm{X}^{2} \\
& +1.67110^{-2} \mathrm{X}^{3}-2.70610^{-3} \mathrm{X}^{4} \\
Y= & 1.808+0.449 \mathrm{X}+3.92710^{-2} \mathrm{X}^{2} \\
& -8.57410^{-3} \mathrm{X}^{3}-4.82610^{-3} \mathrm{X}^{4}
\end{aligned}
$$

where $\mathrm{Y}=\log _{10}(<\mathrm{Chl}\rangle_{\text {tot }}$ and $\mathrm{X}=\log _{10}\left(\mathrm{Chl}_{<s a t>}\right)$; equations $(\mathrm{A} 10 \mathrm{a})$ and $(\mathrm{A} 1 \mathrm{Ob})$ are for uniform and nonuniform profiles, respectively (see Figure 1a). For practical application these polynomials reproduce the computed $\langle\mathrm{Chl}\rangle_{\text {tot }}$ values within $2 \%$ in the $\mathrm{Chl}_{\text {«sat }}$ range from 0.02 to $20 \mathrm{mg} \mathrm{Chl} \mathrm{m}^{-3}$.

\section{Appendix C: Estimating PAR( $\left.0^{+}\right)$}

The reduction of the incident total radiation due to the presence of clouds is estimated according to the formulation of Reed [1977]

$$
\operatorname{SW}\left(0^{+}\right)=\operatorname{SW}\left(0^{+}\right)_{\text {clear }}[1-\Delta]
$$

with

$$
\Delta=0.632 \mathrm{c}-0.0019 \alpha
$$

$\mathrm{SW}\left(0^{+}\right)_{\text {clear }}$ and $\mathrm{SW}\left(0^{+}\right)$are the total solar radiation $(300-2500$ $\mathrm{nm}$ ) at the surface level, under clear and cloudy skies, respec- tively, $\mathrm{c}$ is the cloudiness index, varying from 1 for an overcast sky to 0 for a clear sky, and $\alpha$ is the solar elevation at noon (in degrees). As far as only PAR $\left(0^{+}\right)(400-700 \mathrm{~nm})$ is concerned, the above expression has to be modified to account for the less severe reduction by clouds of the visible radiation, assumed to be only 75\% of that for the long-wave domain. As a consequence, the reduction for the long-wave radiation (if considered) should be correlatively increased, to ensure that the global reduction for the whole solar radiation remains consistent with the Reed's formula. It follows that

$$
\operatorname{PAR}\left(0^{+}\right)=\operatorname{PAR}\left(0^{+}\right)_{\text {clear }}\left[1-\frac{0.75 \Delta}{\left(1-0.25 \mathrm{~F}_{\text {vis }}\right)}\right]
$$

where $F_{\text {vis }}$ is the fraction of total radiation which falls within the $400-700 \mathrm{~nm}$ domain; $F_{\text {vis }}$ is set at 0.46 [Pinker and Lazslo, 1992]. As in Reed, a constant reduction of $5 \%$ is applied to $\operatorname{PAR}\left(0^{+}\right)_{\text {clear }}$ when $\mathrm{c}$ is lower than 0.28 , and more generally if the above bracketed expression in (A12) becomes greater than 0.95 . These reductions are considered as wavelength independent and equally apply to all bands within the visible domain. In order to derive the irradiance just beneath the surface (at $0^{-}$), the loss by specular reflection at the air-water interface is considered as constant $(6.6 \%)$ for the diffuse component (sky radiation), and is made dependent upon the sun angle and the wind speed [Austin, 1974] for the direct sun radiation.

\section{Appendix D: Standard Conditions Adopted When Generating the Tables and Computing $P$}

\author{
Physiology \\ $\alpha^{\prime}=\mathrm{a}_{\text {max }}^{*} \varphi_{\mu, \max }$

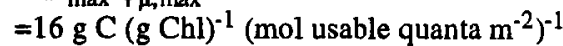 \\ $\approx 6.4 \mathrm{~g} \mathrm{C}\left(\mathrm{g} \mathrm{Chl}^{-1} \text { (mol available quanta } \mathrm{m}^{-2}\right)^{-1}$ \\ $A^{*}(\lambda)=$ solid curve in Figure 3 . \\ Photosynthesis - Irradiance relationship : equation A6a, with $\beta=$ \\ 0.01 . \\ $\operatorname{KPUR}\left(20^{\circ}\right) \quad=80 \mu \mathrm{mol}$ quanta $\mathrm{m}^{-2} \mathrm{~s}^{-1}$ \\ Temperature effect : equation $\mathrm{A} 8$ \\ $\mathrm{Q}_{10} \quad=1.88$ (reference temperature $20^{\circ} \mathrm{C}$ )

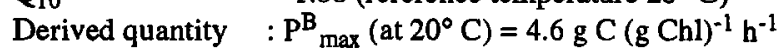

\section{PAR computations}

Geography, Astronomy :

Ellipticity of the Earth's orbit and declination of the Sun : Spencer [1971]

Dates : the twenty-first day of each month (when day length exceeds 2 hours)

Atmosphere :

Clear atmosphere barometric pressure $1013 \mathrm{~h} \mathrm{~Pa}$ total ozone content $350 \mathrm{DU}$ precipitable water $2 \mathrm{~cm}$ maritime aerosol $23 \mathrm{~km}$ visibility

Reduction factor by clouds : Reeds equation [1977] (see Appendix C)

Wind speed : $4 \mathrm{~m} \mathrm{~s}^{-1}$ 
Increments for integrations

$\begin{array}{ll}\Delta \lambda & =10 \mathrm{~nm} \\ \Delta t & =1 / 30 \text { Daylength } \\ \Delta z & =1 / 75 \mathrm{D} \\ \mathrm{D} & =\text { depth of the productive layer (down to the } 0.1 \% \text { PAR } \\ & \text { level). }\end{array}$

Acknowledgments. The authors would like to express their appreciation to two anonymous reviewers for valuable criticism and suggestions. We acknowledge support of the European community, through the contract ESCOBA-EV5V-CT92-0124.

\section{References}

André, J.M., Ocean color remote-sensing and the subsurface vertical structure of phytoplankton pigments, Deep Sea Res part A., 39, 763$779,1992$.

Antoine, D., J. M. André, and A. Morel, Oceanic primary production, 2, Estimation at global scale from satelite (coastal zone color scanner) chlorophyll, Global Biogeochem. Cycles, this issue, 1995.

Antoine, D., A. Morel, and J.M. André, Algal pigment distribution and primary production in the Eastern Mediterranean as derived from Coastal Zone Color Scanner observations, J. Geophys. Res., 100, 16,193-16,209, 1995.

Austin, R. W., The remote sensing of spectral radiance from below the ocean surface, in Optical Aspects of Oceanography, edited by N. G. Jerlov, and E. S. Nielsen, pp. 317-344, Academic, San Diego, Calif., 1974.

Bannister, T. T., Production equations in terms of chlorophyll concentration, quantum yield, and upper limit to production, Limnol. Oceanogr., $19,1-12,1974$.

Berthon, J. F., and A. Morel, Validation of a spectral light-photosynthesis model and use of the model in conjunction with remotely sensed pigment observations, Limnol. Oceanogr., 37, 781-796, 1992.

Bishop, J. K. B., and W. B. Rossow, Spatial and temporal variability of global surface solar irradiance, J. Geophys. Res., 96, 16,839-16,858, 1991.

Bricaud, A., and A. Morel, Light attenuation and scattering by phytoplanktonic cells : A theoretical modeling, Appl. Opt., 25, 571$580,1986$.

Bricaud, A., A. L. Bédhomme, and A. Morel, Optical properties of diverse phytoplanktonic species : Experimental results and theoretical interpretation, J. Plank. Res., 10, 851-873, 1988.

Bricaud, A., M. Babin, A. Morel, and H. Claustre, Variability in the chlorophyll-specific absorption coefficients of natural phytoplankton : Analysis and parameterization, J. Geophys. Res., 100, 13,321-13,332, 1995.

Claustre, H., and J. C. Marty, Specific phytoplankton biomasses and their relation to primary production in the tropical north Atlantic, Deep Sea Res., in press, 1995.

Cullen, J.J., The deep chlorophyll maximum : Comparing vertical profiles of chlorophyll a, Can. J. Fish. Aquat. Sci., 39, 791-803, 1982.

Cullen, J. J., On models of growth and photosynthesis in phytoplankton, Deep Sea Res., 37, 667-683, 1990.

Cullen, J.J., X. Yang, and H.L. MacIntyre, Nutrient limitation of marine phtosynthesis, in Primary Productivity and Biogeochemical Cycles in the Sea, edited by P.G. Falkowski and A.D. Woodhead, vol. 43, pp. 69-88, Plenum, New York, 1992.

Dandonneau, Y., and A. LeBouteiller, A simple and rapid device for measuring planktonic primary production by in situ sampling, and ${ }^{14} \mathrm{C}$ injection and incubation, Deep Sea Res. Part A, 39, 795-803, 1992.

Dubinsky, Z., P.G. Falkowski, and K. Wyman, Light harvesting and utilization by phytoplankton, Plant Cell Physiol., 27, 1335-1349, 1986.

Eppley, R. W., Temperature and phytoplankton growth in the sea, Fish. Bull., 70, 1063-1084, 1972.

Falkowski, P. G., Light-shade adaptation and assimilation numbers, $J$. Plank. Res., 3, 203-216, 1981.

Frouin, R., D. W. Lingner, C. Gautier, K. S. Baker, and R. C. Smith, A simple analytical formula to compute clear sky total and photosyntheti- cally available solar irradiance at the ocean surface, J. Geophys. Res., 94, 9731-9742, 1989.

Geider, R.J.,. Quantitative phytoplankton physiology : Implications for primary production and phytoplankton growth, in Proceedings of Measurement of Primary Production From the Molecular to the Global Scale, edited by W.K.W. Li and S.Y. Maestrini, pp. 52-62, La Rochelle, France, 21-24 April 1992, Int. Counc. for the Explor. of the Sea, 1993.

Gilstad, M. and E. Sakshaug, Growth rates of ten diatoms species from the Barents sea at different irradiances and day lengths, Mar. Ecol. Prog. Ser., 64, 169-173, 1990.

Gordon, H. R., and W. R. McCluney, Estimation of the depth of sunlight penetration in the sea for remote sensing, Appl. Opt., 14, 413-416, 1975.

Gregg, W. W., and K. L. Carder, A simple spectral solar irradiance model for cloudless maritime atmospheres, Limnol. Oceanogr., 35, 1657 $1675,1990$.

Herbland, A., The deep phaeopigments maximum in the ocean : Reality or illusion?, in Toward a Theory on Biological-Physical Interactions in the World Ocean, edited by J. Rothschild, Kluwer Academic, Norwell, Mass., 1988.

Jassby, A. D., and T. Platt, Mathematical formulation of the relationship between photosynthesis and light for phytoplankton, Limnol. Oceanogr., 21, 540-547, 1976.

Kiefer, D. A., and B. G. Mitchell, A simple, steady state description of phytoplankton growth based on absorption cross section and quantum efficiency, Limnol. Oceanogr., 28, 770-776, 1983.

Kirk, J. T. O., Light and Photosynthesis in Aquatic Ecosystems, 401 pp., Cambridge University Press, New York 1983.

Levitus, S., Climatological atlas of the world ocean, U.S. Govt. Print. Off., Washington D.C., NOAA Prof. Pap., 13, 1982.

Morel, A., Available, usable, and stored radiant energy in relation to marine photosynthesis, Deep Sea Res., 25, 673-688, 1978.

Morel, A., Optical modeling of the upper ocean in relation to its biogenous matter content (case 1 waters), J. Geophys. Res., 93, $10,749-10,768,1988$.

Morel, A., Light and marine photosynthesis : A spectral model with geochemical and climatological implications, Prog. Oceanogr., 26, 263306, 1991.

Morel, A., and J. M. André, Pigment distribution and primary production in the western Mediterranean as derived and modeled from coastal zone color scanner observations, J. Geophys. Res., 96, 12,685-12,698, 1991.

Morel, A., and J. F. Berthon, Surface pigments, algal biomass profiles, and potential production of the euphotic layer : Relationships reinvestigated in view of remote-sensing applications, Limnol. Oceanogr., 34, 1545-1562, 1989.

Morel, A., L. Lazzara, and J. Gostan, Growth rate and quantum yield time response for a diatom to changing irradiances (energy and color), Limnol. Oceanogr., 32, 1066-1084, 1987.

Morel, A., Y. Ahn, F. Partensky, D. Vaulot, and H. Claustre, Prochlorococcus and synechococcus : A comparative study of their optical properties in relation to their size and pigmentation, J. Mar. Res. 51, 617-649, 1993.

Ondrusek, M. E., R. R. Bidigare, S. T. Sweet, D.A. Defreitas, and J. M. Brooks, Distribution of phytoplankton pigments in the North Pacific ocean in relation to physical and optical variability, Deep Sea Res., 38, 243-266, 1991.

Pinker, R. T., and I. Laszlo, Global distribution of photosynthetically active radjation as observed from satellites, J. Cli., 5, 56-65, 1992.

Platt, T., The concept of energy efficiency in primary production, Limnol. Oceanogr., 14, 653-659, 1969.

Platt, T., and S. Sathyendranath, Oceanic primary production : Estimation by remote sensing at local and regional scales, Science, 241, 1613$1620,1988$.

Platt, T., C. L. Gallegos, and W. G. Harrison, Photoinhibition of photosynthesis in natural assemblages of marine phytoplankton, J. Mar. Res., $38,687-701,1980$.

Reed, R. K., On estimating insolation over the ocean, J. Phys. Oceanogr. 7, 482-485, 1977

Ryther, J.H., and C.S. Yentsch, The estimation of phytoplankton production in the ocean from chlorophyll and light data, Limnol. Oceanogr., 2, 281-286, 1957 
Schiffer, R. A., and W. B. Rossow, The International Satellite Cloud Climatology Project (ISCCP) : The first project of the World Climate Research Programme, Bull. Am. Meteorol. Soc., 64, 779-784, 1983.

Schiffer, R. A., and W. B. Rossow, ISCCP global radiance data set : A new resource for climate research, Bull. Am. Meteorol. Soc., 66, 1498$1505,1985$.

Schofield, O., B. B. Prezelin, R. R. Bidigare, and R. C. Smith, In situ photosynthetic quantum yield, Correspondance to hydrographic and optical variability within the Southern Californja bight, Mar. Ecol. Prog. Ser., 93, 25-37, 1993.

Spencer, J.W., Fourier series representation position of the sun, Search, 2, 172,1971 .

Sukenik A., J. Bennett, and P.G. Falkowski, Light-saturated photosynthesis - limitation by electron transport or carbon fixation ? Biochim. Biophys. Acta, 891, 205-215, 1987.

Talling, J.F., The phytoplankton population as a compound photosynthetic system, New Phytol., 56, 133-149, 1957.

Tanré, D., M. Herman, P. Y. Deschamps, and A. DeLeffe, Atmospheric modelling for space measurements of ground reflectances, including bidirectional properties, Appl. Opt., 18, 3587-3594, 1979.

Tanré, D., C. Deroo, P. Duhaut, M. Herman, J. J. Morcrette, J. Perbos, and P. Y. Deschamps, Description of a computer code to simulate the satellite signal in the solar spectrum : The $5 \mathrm{~S}$ code, Int. J. Remote sens., $11,656-668,1990$.
Vernet, M., and C. S. Lorenzen, The presence of chlorophyll $b$ and the estimation of phaeopigments in marine phytoplankton, J. Plank. Res. 9, 255-265, 1987.

Webb, W. L., M. Newton, and D. Starr, Carbon dioxide exchange of Alnus rubra : A mathematical model, Ecologia, 17, 281-291, 1974.

Wozniak, B., J. Dera, and O. Koblentz-Mischke, Modeling the relationship between primary production, optical properties and nutrients in the sea (as a basis for indirectly estimating primary production), Ocean Opt. 11, Proc. SPIE Int. Soc. Opt. Eng., 1750, 246275, 1992.

Yentsch, C. S., Some aspects of the environmental physiology of marine phytoplankton : A second look., Oceanogr. Mar. Biol. Ann. Rev., 12, 41-75, 1974.

Yentsch, C. S., and D. W. Menzel, A method for the determination of phytoplankton chlorophyll and phaeophytin by fluorescence, Deep Sea Res. Oceanogr. Abstr., 10, 221-231, 1963.

D. Antoine and A. Morel, Laboratoire de Physique et Chimie Marines, Université Pierre et Marie Curie et CNRS, BP 8, Quai de la Darse, F 06230, Villefranche sur Mer, France. (e-mail : david@ccrv.obs-vlfr.fr ; morel@ccrv.obs-vlfr.fr)

(Received October 28, 1994; revised September 8, 1995; accepted September 13, 1995.) 